\title{
Crítica da cobertura jornalística nos 30 anos da coluna de ombudsman da Folha de S. Paulo ${ }^{1}$
}

\author{
Diana AZEREDO ${ }^{2}$ \\ Gislene da SILVA ${ }^{3}$
}

\begin{abstract}
Resumo:
Precursor na América Latina e em países lusófonos, o jornal Folha de S. Paulo instituiu o cargo de ombudsman em 24 de setembro de 1989. Ao se completarem três décadas dessa experiência de crítica de mídia, este artigo tem como objetivo sintetizar resultados de uma pesquisa mais ampla a respeito dos principais temas e problemas criticados nas colunas semanais durante esses 30 anos. O corpus total de 1.346 colunas de ombudsman publicadas no período e disponibilizadas no site do jornal foi tratado primeiramente via cinco categorias (fonte principal, foco, tema e abordagem da coluna e intensidade da crítica) que possibilitaram selecionar o conjunto de 71 colunas com críticas fortes à cobertura jornalística da Folha. Nelas, foram identificados seis problemas criticados pelos ombudsmans: falta de informações, destaque para informação de pouca relevância, informações distorcidas, informações erradas, falta de destaque para informação relevante e tratamento desigual para situações equivalentes.
\end{abstract}

Palavras-chave: Jornalismo. Crítica. Cobertura jornalística. Ombudsman. Folha de S. Paulo.

\section{Criticism of news press coverage in the 30 years of the Folha de $S$. Paulo's news ombudsman column}

\begin{abstract}
:
Forerunner in Latin America and lusophone countries, the newspaper Folha de S. Paulo instituted the office of news ombudsman on September 24, 1989. After completing three decades of this experience of media criticism, this article aims to synthesize results of a research about the main topics and issues criticized in the weekly columns during these 30 years. The total corpus of 1,346 ombudsman columns published in the period and made available on the newspaper's website was first handled via five categories (main source, focus, theme and approach of the column and intensity of criticism) that made it possible to select the set of 71 columns with strong criticisms of Folha's journalistic coverage. In them, six problems were criticized by the ombudsmen: lack of information, emphasis on information of little relevance, distorted information, wrong information, lack of emphasis for relevant information and unequal treatment for equivalent situations.
\end{abstract}

Keywords: Journalism. Criticism. News press coverage. News ombudsman. Folha de S. Paulo.

\footnotetext{
1 Artigo produzido com apoio de bolsa oferecida pela Coordenação de Aperfeiçoamento de Pessoal de Nível Superior (Capes).

2 Jornalista graduada pela Universidade de Santa Cruz do Sul e mestre pelo Programa de Pós-Graduação em Jornalismo da Universidade Federal de Santa Catarina (UFSC). E-mail: azeredo_diana@yahoo.com.br

3 Professora Titular do Departamento de Jornalismo da Universidade Federal de Santa Catarina (UFSC). Doutora pelo Programa de Estudos Pós-Graduados em Ciências Sociais (Antropologia) da PUC de São Paulo.E-mail: gislenedasilva@gmail.com
} 


\title{
Críticas a la cobertura periodística en los 30 años de la columna del defensor del público de Folha de S. Paulo
}

\begin{abstract}
Resumen:
Precursor en América Latina y en los países de habla portuguesa, el periódico Folha de S. Paulo instituyó el cargo de defensor del público el 24 de septiembre de 1989. Después de completar tres décadas de esta experiencia de crítica de los medios, este artículo tiene como objetivo resumir los resultados de una investigación. Una visión más amplia de los principales temas y problemas criticados en las columnas semanales durante estos 30 años. El corpus total de 1.346 columnas del defensor del público publicadas en el período y disponibles en el sitio web del periódico se trató principalmente a través de cinco categorías (fuente principal, enfoque, tema y enfoque de la columna e intensidad de la crítica) que permitieron seleccionar el conjunto de 71 columnas con fuertes críticas a la cobertura de noticias de Folha. En ellos, los defensores del público criticaron seis problemas: falta de información, énfasis en información de poca relevancia, información distorsionada, información incorrecta, falta de énfasis en información relevante y tratamiento desigual para situaciones equivalentes.
\end{abstract}

Palabras clave: Periodismo. Crítica. Cobertura de noticias. Defensor del público. Folha de S. Paulo.

\section{Introdução}

Entende-se que tão necessário quanto a cobertura jornalística mostrar os problemas da sociedade é o jornalismo fazer a autocrítica de sua prática, reconhecendo os próprios erros. Essa disposição para prestar contas e demonstrar transparência perante o público resulta no aumento da credibilidade, valor tão caro ao exercício profissional. Em 30 anos de ombudsman na imprensa brasileira, latino-americana e de língua portuguesa, esta pesquisa justifica-se pela necessidade de pensar sobre e aprimorar estudos de crítica jornalística.

Resultado de trabalho investigativo realizado durante o mestrado, este artigo tem como objeto de estudo a crítica da cobertura jornalística nos 30 anos da coluna de ombudsman da Folha de S. Paulo e visa a apresentar os problemas mais abordados nos textos publicados semanalmente. A fim de cumprir esses objetivos de apresentação e leitura, a opção foi pela análise de conteúdo (BARDIN, 1977) a partir de um protocolo de seleção com cinco filtros (fonte principal, foco, tema e abordagem da coluna e intensidade da crítica). Aplicados ao corpus total de 1.346 colunas de ombudsman publicadas de setembro de 1989 a abril de 2019 e disponibilizadas no site do jornal, esses cinco critérios possibilitaram a seleção dos textos de forma a delimitar um conjunto de 71 colunas com críticas fortes à cobertura jornalística da Folha.

Os conteúdos desses textos foram sintetizados em um quadro com quatro categorias (título da coluna, data de publicação, tema da cobertura criticada e problema criticado) e organizados por temas (política, cotidiano, artes e entretenimento, internacional, economia, poder Judiciário e segurança pública). Os problemas criticados 
distribuem-se nas seguintes subcategorias: falta de informações, destaque para informação de pouca relevância, informações distorcidas, informações erradas, falta de destaque para informação relevante e tratamento desigual para situações equivalentes. Sobre esse corpus final, foi realizada, na dissertação (AZEREDO, 2019b), uma leitura em profundidade, quando se verificou, além de outros resultados, a predominância do problema da falta de informações.

Considerando-se aqui as limitações do artigo, foi feito um esforço no sentido de oferecer, de forma sintética, um panorama da produção de ombudsman entre setembro de 1989 e abril de 2019. A fim de melhor situar os resultados, desenvolvem-se, na sequência, breves reflexões sobre a crítica jornalística e as implicações do termo ombudsman, que, na imprensa, corresponde tanto à função de crítico quanto à de ouvidor. Após a explicitação do percurso metodológico, são discutidos os principais temas e problemas criticados nas colunas.

\section{Apontamentos sobre crítica jornalística}

Bittencourt (2014) contribui, notavelmente, para proporcionar uma visão ampla acerca do processo crítico que tem como objeto o jornalismo moderno - nascido e consolidado a partir do século XIX. A pesquisadora recorda que mesmo as atividades pré-jornalísticas, sem periodicidade, no século XVI, já “despertavam a atenção de autoridades, que criavam mecanismos como licenciamento e censura prévias para controlar a circulação de opiniões e informações" (BITTENCOURT, 2014, p. 21-22).

Fazendo referência aos autores Bertrand (2002), Traquina (2012) e Oliveira (2007), Bittencourt (2014) chama a atenção para a existência de uma avaliação acerca das publicações jornalísticas entre os séculos XVII e XIX, quando as veiculações nem haviam tomado a forma moderna como é reconhecida atualmente. Depois de líderes religiosos e políticos, no início do século XX, é a vez de grandes nomes da literatura investirem esforços críticos contra o jornalismo. Dedicados ao registro das atualidades e, na maioria dos casos, comprometidos com interesses econômicos que visualizavam nas notícias uma mercadoria capaz de gerar lucro, os jornalistas costumavam ser taxados de vulgares, superficiais e corrompidos (BITTENCOURT, 2014).

“A crítica das práticas midiáticas ensaiaria uma aproximação com a atual media criticism por meio de um trabalho desenvolvido, em 1920, pelos jornalistas norteamericanos Walter Lippmann e Charles Merz", registram Bittencourt e Silva (2015, p. 
8). Elas se referem ao estudo que a dupla realizou sobre a cobertura da Revolução Russa pelo The New York Times. Nos Estados Unidos, outro passo relevante demorou quase três décadas para ser dado, com o estudo conhecido como Comissão de Hutchins. "Anos depois da divulgação do relatório da Comissão Hutchins, diferentes mecanismos voltados à crítica da mídia foram desenvolvidos nos Estados Unidos, importados por outros países, como é o caso do Brasil”, relaciona Bittencourt (2014). Um exemplo é a criação do cargo de ombudsman. No ocidente, o primeiro veículo a implementar a novidade foi o Courier-Journal, de Louisville (EUA), em 1967, com John Herchenroeder repassando para a redação, internamente, as manifestações dos leitores.

No Brasil, esse movimento ganha forte repercussão por meio de Alberto Dines. Porém, ele mesmo reconhece que já havia crítica de mídia no território nacional antes de suas iniciativas. Para Dines (1982), a primeira voz brasileira que teve a ousadia de criticar a imprensa foi a de Lima Barreto, com o livro Recordações do escrivão Isaías Caminha. Dos anos 1940, 1950 e 1960, Dines (1982) lista os críticos Gondim da Fonseca (principalmente no jornal $O$ Mundo) e Otávio Malta e Paulo Francis (no impresso A Última Hora). Carrato (2002) acrescenta os nomes de Sérgio Augusto (que analisava a imprensa na década de 1970, no Pasquim) e Sinval Itacambira Leão (líder da equipe que fundou a coluna "O Circo da Notícia" na revista Imprensa).

Tendo realizado um curso na Universidade de Columbia e estágio em jornais dos Estados Unidos, Dines contribuiu de forma significativa para o desenvolvimento da crítica de mídia no Brasil. Ele aplicou seus conhecimentos acerca do media criticism, primeiramente, no Jornal do Brasil $(J B)$ e, depois, em outros veículos nacionais (AZEREDO, 2019a). Em 1996, Dines, com os professores Carlos Vogt e José Marques de Melo, deu início ao site Observatório da Imprensa $(\mathrm{OI})^{4}$. Fórum permanente de debate sobre a mídia, a página reúne textos de jornalistas, cientistas e leitores comuns. Além das manifestações escritas, as mensagens são transmitidas por meio de vídeos e áudios.

Bittencourt (2014) comenta que o OI inspirou a criação de outros observatórios, coordenados por universidades ou entidades civis brasileiras. Segundo a pesquisadora, em 2005, foi criada a Rede Nacional de Observatório da Imprensa (Renoi), "uma associação colaborativa dedicada ao fortalecimento da crítica produzida dentro e fora do ambiente acadêmico" (BITTENCOURT, 2014, p. 39). Na página online 5 , a mais recente

4 Página disponível em: http://observatoriodaimprensa.com.br/ Acesso em: 17 mar. 2018.

5 Disponível em: http://renoi.blogspot.com/ Acesso em: 17 mar. 2019. 
atualização foi feita em dezembro de 2013 e anunciava o encerramento do ano com 15 observatórios. A Renoi mantém um fórum regular no âmbito da Associação Brasileira de Pesquisadores em Jornalismo (SBPJor).

No contexto não apenas nacional, mas também da América Latina e dos países lusófonos, a Folha de S. Paulo foi precursora na implementação do cargo de ombudsman, em 24 de setembro de 1989, com o jornalista Caio Túlio Costa como primeiro responsável pela função (atualmente desempenhada pela jornalista Flavia Lima, $14^{a}$ profissional titular da coluna). Há 30 anos, a data coincidiu com o período de reabertura democrática no Brasil e de críticas à imprensa e com o início das discussões acerca dos direitos do consumidor.

\section{Ombudsman como crítico e ouvidor}

Importa observar que o termo escandinavo ombudsman, instituído na Suécia em 1809, remetia ao cargo de representante do povo perante autoridades do regime monárquico-parlamentar (MENDES, 2002). Embora pouco popular na língua portuguesa, a palavra não pode ser substituída, simplesmente, por ouvidor ou crítico. $\mathrm{Na}$ imprensa, o ombudsman desempenha ambas as funções. Além de receber reclamações, dúvidas e elogios do público e encaminhar demandas, esse jornalista também publica uma avaliação, geralmente, semanal acerca da produção jornalística do veículo que o contratou.

Conforme Mesquita (2002, p. 232), trata-se do "papel, de algum modo, de 'traidor institucional', em nome da 'cumplicidade com o leitor"'. "Enquanto cronista, possui carta branca para criticar seu próprio jornal e, em certos casos, os outros meios de comunicação de massa. [...] Sua principal força consiste em poder criticar em suas próprias páginas" (MESQUITA, 2002, p. 233). Ele estuda a implantação de ombudsman nos jornais portugueses a partir de 1997 e enumera sete níveis de ação do profissional:

Ele discute o jornal em suas próprias páginas, prolongando no espaço público o debate sobre as decisões editoriais que tradicionalmente não saía das redações e do meio jornalístico (função crítica e simbólica); Estabelece uma ponte com os leitores, respondendo às reclamações e às críticas (função mediadora); Cuida da retificação dos dados inexatos e incompletos, apelando, se necessário, para peritos (função corretiva); Recomenda à hierarquia medidas destinadas a reparar atos suscetíveis de lesar os direitos dos leitores (função persuasiva); Explica aos leitores os mecanismos da produção jornalística, desde a relação com as fontes até a seleção das informações (função pedagógica); Ele pode, por sua crítica, influenciar (eventuais) decisões dos editores e jornalistas (função dissuasiva); Pode favorecer o debate sobre temas políticos, econômicos e sociais (função 
cívica). (MESQUITA, 2002, p. 235-236, grifos do autor).

Não basta receber as queixas e orientar os leitores a encaminhar cartas ao editor, explica Loures (2008):

O ombudsman, por sua vez, desempenha funções mais amplas: ouve as reclamações dos leitores, investiga os comentários e queixas sobre o conteúdo do jornal e aponta, seja por meio de memorandos internos, seja em sua coluna semanal, os erros encontrados nas edições diárias, recomendando ações corretivas. Além da autocrítica da empresa jornalística, alguns ombudsmen, como é o caso do que ocupa o cargo no jornal Folha de S. Paulo, fazem ainda no espaço destinado à sua coluna a crítica dos meios de comunicação, participam de conferências e, quando for o caso, defendem o jornal publicamente. (LOURES, 2008, p. 169).

Seguindo esse raciocínio, Coelho (2013) lista:

Não há um consenso generalizado em relação à forma como deve atuar um ombudsman, mas algumas das práticas comumente adotadas por ouvidores de mídia são: analisar e monitorar os conteúdos publicados; investigar e responder comentários recebidos; obter explicações dos funcionários envolvidos; produzir relatórios sobre as reclamações dos leitores; promover eventos que debatam temas relacionados à ética e à deontologia. (COELHO, 2013, p. 16).

Essa variação, segundo Mesquita (2002), pode ser identificada tanto no desempenho do ombudsman quanto na percepção que se tem dele:

Evidentemente, alguns suspeitam de que ele não é senão um instrumento estratégico da empresa, ou mesmo "o defensor da linha editorial". Mas outros insistem sobre o lugar privilegiado do qual ele fala: com efeito, o mediadorjornalista conhece bem os mecanismos de produção das informações e de controle interno das redações, o que lhe permite analisar com pleno conhecimento de causa situações complexas. (MESQUITA, 2002, p. 235, aspas do autor).

Sob o ponto de vista de Braga (2006), as negociações e tensões ocorrem nos dois processos críticos: o interno e o externo. Tanto as análises e questionamentos tratados entre colegas quanto aqueles que são expostos aos leitores trazem, na essência, uma discussão em relação aos critérios críticos. Ao propor uma reflexão sobre a prática, colegas jornalistas partem dos mesmos padrões, mas vistos em suas nuances.

No entender de Braga (2006), os critérios são matizados pelo exercício diário e pelas interpretações individuais. Por essa razão, na coluna do ombudsman, ainda que transpareçam as polêmicas, o tom tende a ser mais compreensivo e negociado. $O$ embate frontal é atenuado pelo entendimento mútuo de que, sim, há regras comuns na profissão, porém, nem sempre inequívocas ou indiscutíveis. Possivelmente, em virtude 
disso, entre as 590 colunas com críticas à cobertura da Folha, 427 (72\%) foram categorizadas como moderadas e $92(15,5 \%)$ como fracas. As 71 (12\%) críticas fortes correspondem à menor ocorrência.

\section{Percurso metodológico}

Entre as escolhas que possibilitaram partir do corpus total de 1.346 colunas de ombudsman e chegar ao corpus das 71 com críticas fortes à cobertura da Folha de S. Paulo está o "conjunto de técnicas" definido por Bardin (1977, p. 31) como análise de conteúdo. Fundamentado nessa base metodológica e tendo em vista propostas como a de Silva e Calero (2018), foi elaborado o protocolo de seleção com cinco critérios a fím de categorizar as colunas disponíveis no site da Folha.

$\mathrm{O}$ primeiro filtro identificou a fonte principal do parecer: interna (se era o ombudsman, majoritariamente, o responsável pelos comentários) ou externa (foram descartadas as colunas que, na sua maior parte, eram constituídas por manifestações de leitores, fontes, colegas e estudiosos). Em segundo lugar, foi identificado o foco da coluna, eliminando as que avaliavam a imprensa em geral e mantendo aquelas destinadas a julgar especificamente a Folha.

$\mathrm{Na}$ sequência, tomou-se como critério o tema da coluna, que podia variar entre tratamento de erros e das manifestações dos leitores; a postura empresarial, interna e externa, no contexto jurídico, econômico e político; aspectos gráfico-editoriais; aspectos administrativos relacionados a assinaturas, anúncios, brindes, circulação, Datafolha, comentários no site e nas redes sociais; publicações que não reuniam elementos suficientes para serem consideradas notícias ou coberturas jornalísticas, como quadrinhos, charges, colunas, blogs, críticas, obituários, cadernos/suplementos especiais de serviço e programas audiovisuais; e a cobertura jornalística. Selecionadas apenas as colunas que tratavam da cobertura jornalística, a quarta etapa buscou averiguar se a abordagem era crítica ou elogiosa.

Por fim, o quinto filtro utilizado na análise foi a intensidade da crítica. A classificação em fortes, moderadas e fracas tem como critério a presença dos seguintes fatores atenuantes da critica: ausência do problema criticado no título; mesmo erro cometido por outros veículos; presença de justificativa; aceitação da justificativa e/ou aspectos elogiados na cobertura. São situações nas quais a crítica ia sendo enfraquecida. Foram definidas como críticas fortes aquelas em que o problema criticado estava 
presente no título da coluna, só a Folha erra, não há justificativa ou há justificativa (apresentada pela Secretaria de Redação ou por jornalistas responsáveis pelo erro), mas ela não é aceita pelo ombudsman. Por exemplo, quando o problema era mencionado no título da coluna, mas o ombudsman denunciava outros veículos por cometerem aquele erro, a crítica foi considerada moderada. Caso o problema estivesse citado no título, mas nem só a Folha errasse e houvesse aspectos elogiados na cobertura, a crítica foi categorizada como fraca.

Dessa maneira, foi possível detectar 71 colunas com críticas fortes à cobertura jornalística da Folha. Esses textos, por sua vez, foram identificados conforme a data de publicação, o título, o tema da cobertura criticada (política, economia, segurança pública, poder Judiciário, cotidiano, artes e entretenimento ou internacional) e o problema criticado (falta de informações, destaque para informação de pouca relevância, informações distorcidas, informações erradas, falta de destaque para informação relevante ou tratamento desigual para situações equivalentes).

Antes de passar à apresentação dos 71 textos com críticas fortes, convém fazer uma observação mais abrangente das 1.346 publicações nesses 30 anos. Admite-se que a análise de conteúdo, ao reduzir o corpus e tornar o objeto empírico verificável, ao mesmo tempo exclui elementos também interessantes, mas que demandariam esforço extra para inferir acerca deles.

Em primeiro lugar, já era de se supor que a maioria dos textos teria como fonte principal pareceres emitidos pelo ombudsman, que é o titular da coluna. Nesta pesquisa, surpreendeu encontrar 53 apreciações majoritariamente escritas por leitores, fontes, colegas do ombudsman e estudiosos. Uma possível justificativa para o caso das manifestações de autoria do leitorado é o frequente conflito ${ }^{6}$ quanto ao pouco espaço no Painel do Leitor, gerando uma demanda maior na seção de ombudsman - alguns ombudsmans $^{7}$ chegaram a disponibilizar, nas suas próprias colunas dominicais, a oportunidade para que quem lesse a Folha pudesse se manifestar integralmente naquele local. Quando verificadas situações como essas, as colunas foram descartadas desta pesquisa.

Quanto ao foco das colunas publicadas durante as três décadas, já se tinha uma expectativa de que a maioria das apreciações iria se referir especificamente à Folha de

6 Uma coluna com essa disputa pelo Painel do Leitor está disponível em: https://www1.folha.uol.com.br/fsp/ombudsma/om1811200701.htm. Acesso em: 20 jul. 2019.

7 Sendo um termo de origem sueca (e não inglesa), opta-se pela expressão ombudsman para ambos os gêneros e ombudsmans no plural (AZEREDO, 2019b). 
S. Paulo. Sendo a empresa responsável pela contratação e manutenção de críticos e ouvidores, dispondo-se a assumir e discutir erros em público, é razoável que se torne o alvo preferencial das avaliações de ombudsman.

Em relação ao tema da coluna, a ênfase foi a cobertura jornalística, entendida aqui como sinônimo de notícia - já que notícia é um conceito central na teoria do jornalismo (GENRO FILHO, 2012; LAGE, 1979). Sendo o ombudsman um jornalista, com a mesma formação acadêmica básica dos seus colegas, demonstra aptidão para julgar a produção noticiosa com base em valores compartilhados entre profissionais e estudiosos do campo, tais como interesse público, imparcialidade, pluralismo e divulgação de informações corretas (bem apuradas, checadas e hierarquizadas).

\section{Principais problemas observados}

Nem mesmo na dissertação seria viável aprofundar os temas das coberturas criticadas nas 590 colunas. Cabe, porém, ressaltar que um aspecto chamou a atenção na leitura realizada: mais de 40 críticas condenavam problemas causados pela linha editorial com tendências conservadoras e neoliberais. Entre 1989 e 2019, foram apontados erros no noticiário sobre regulamentação da mídia, denúncias de corrupção contra o Partido dos Trabalhadores (PT) e o Partido da Social Democracia Brasileira (PSDB), greves de professores e demais trabalhadores, conflitos em universidades públicas, movimento sindical, privatizações, políticas públicas para acabar com a fome, políticas afirmativas, Programa Mais Médicos, políticos condenados por corrupção, Hugo Chávez e Venezuela, ativista Cesare Battisti, usuários de crack, moradores de rua e áreas periféricas, indígenas, negros, mulheres e outras minorias ${ }^{8}$. É de se observar a existência de críticas relacionadas ao viés oposto, acusando a cobertura de favorecer causas progressistas, como a denúncia de violência policial, a não redução da

\footnotetext{
${ }^{8}$ Colunas que criticam a cobertura de favorecer causas conservadoras e neoliberais estão disponíveis em: https://www1.folha.uol.com.br/colunas/caiotuliocosta/1991/09/1521094-relatorio-final.shtml; https://wwwl.folha.uol.com.br/fsp/ombudsman/142645-perder-esse-trem.shtml; https://www1.folha.uol.com.br/colunas/veraguimaraesmartins/2014/06/1466875-faltou-transparenciasobrou-duvidas.shtml;

https://www1.folha.uol.com.br/fsp/ombudsman/97869-a-exumacao-de-chavez.shtml; https://wwwl.folha.uol.com.br/colunas/marceloberaba/2005/02/1520058-a-morte-anunciada-da-meninacaiua.shtml; https://www1.folha.uol.com.br/fsp/ombudsman/96565-os-miseraveis.shtml; https://www1.folha.uol.com.br/colunas/suzanasinger/2013/11/1366057-um-rosto.shtml. Acesso em: 20 jul. 2019.
} 
maioridade penal e o fim da comercialização de armas de fogo e munição ${ }^{9}$. Porém, quando o problema diagnosticado estava relacionado à parcialidade do noticiário, na maioria das vezes, tratava-se de uma parcialidade favorável ao posicionamento conservador.

As possibilidades interpretativas dessas 590 colunas não se esgotam aqui. O material é rico e vasto, permitindo muitas abordagens - especialmente, se for considerado o corpus total de 1.346. Por isso, a aplicação do protocolo de seleção com cinco critérios foi de grande valia para este trabalho.

Dando sequência à apresentação dos principais resultados referentes às 71 colunas com críticas fortes, importa dizer que na primeira década, foram observadas 16 críticas fortes; na segunda década, 29, e, na terceira, 26. Esse resultado sinaliza para a tendência de se criticar a imprensa de forma geral nos primeiros anos de criação do cargo. Entre 1989 e 1998, são mais frequentes as menções aos outros veículos e até mesmo a jornalistas específicos. A partir de 1999, as avaliações passam a se concentrar mais na Folha. Não seria descabido pensar que esse afunilamento de foco tenha sido proposto para evitar polêmicas e ações judiciais.

As coberturas com mais problemas criticados são de política (27) e cotidiano (16), situação que pouco surpreende, pois corresponde aos temas priorizados na cobertura jornalística da Folha e a categoria cotidiano abrange grande variedade de assuntos. Ocorrência não esperada é a do grande número de críticas à cobertura de artes e entretenimento (10) e internacional (10). Arrisca-se supor, primeiramente, que se deve à maior mobilização de leitores, que tendem a perceber mais erros nas notícias relacionadas a artes e entretenimento, que, vale ressaltar, abarca eventos esportivos e atletas. No caso de internacional, três criticam notícias parcialmente desfavoráveis à exUnião das Repúblicas Soviéticas e a Cuba, uma trata de informações distorcidas sobre a União Europeia e as outras seis analisam o noticiário acerca dos Estados Unidos, denotando uma preferência pelo país estadunidense, não somente na cobertura específica, como também na perspectiva (neoliberal) da produção jornalística a respeito de outras nações.

Entre os problemas mais criticados, a falta de informações predomina em todas as décadas. Ela está relacionada a diferentes causas, como parcialidade, oficialismo, plágio

9 Colunas que criticam a cobertura de favorecer causas progressistas estão disponíveis em: https://wwwl.folha.uol.com.br/colunas/bernardoajzenberg/2003/11/1519891-opiniao-e-noticia.shtml; https://www1.folha.uol.com.br/fsp/ombudsma/om2105200601.htm https://wwwl.folha.uol.com.br/fsp/ombudsma/om0910200501.htm. Acesso em: 20 jul. 2019. 
ou omissão da fonte de informação (foi o que ocorreu em maio de 1996, quando a Folha não declarou que as informações haviam sido apuradas por $O$ Globo), falta de didatismo, descuido dos princípios do jornalismo preventivo, insensibilidade, tratamento burocrático da pauta e dependência do jornalismo declaratório. Pode ter tido origem em um erro cometido na apuração (quando o repórter não entrevista, não pesquisa...) ou na edição (quando se tem as informações, mas não se divulga).

O destaque ou a falta de destaque estão associados à edição das informações e à compreensão dos critérios de noticiabilidade. Nos dois casos, quase sempre todas as informações são apuradas e publicadas, porém, com a hierarquização equivocada, causando dificuldades para o leitor discernir o que é ou não importante em determinada notícia. Os equívocos podem ter sido causados pelo excesso ou pela falta de criticidade dos repórteres e responsáveis pela edição ou por preconceitos do jornalista, como apontado na crítica publicada em $1^{\circ}$ de março de 2009 , quando se enfatiza a cirurgia plástica da então ministra Dilma Rousseff na cobertura.

O problema das informações erradas ocorre, em geral, por precipitação, quando a apuração ou a checagem foram insuficientes e o fato noticiado não corresponde à realidade. Essa falha é criticada nas coberturas sobre o enfraquecimento (descrito como fim) da União Soviética, a denúncia de conivência do ministro da Fazenda com gasto excessivo de dinheiro público (acusação não confirmada e conivência nunca provada), definição de candidatura a vice na chapa do PSDB (quando os integrantes do partido optaram por uma candidata que não estava entre os nomes noticiados previamente como possíveis de serem escolhidos) e em outras seis notícias. Esse tipo de erro, presente em todas as décadas, mas predominante na segunda, pode ser causado por confiança excessiva na fonte da informação que, motivada por interesses pessoais ou apenas mal informada, fornece um dado equivocado para o repórter.

Único problema que diminui entre a primeira e a segunda década, as informações distorcidas referem-se a elementos parcialmente verdadeiros, mas que são exagerados ou divulgados com termos imprecisos. Tende a estar relacionado à parcialidade e ao sensacionalismo para chamar a atenção em manchetes. Dois modelos de falha como essa são as notícias sobre a unificação europeia (quando se informou que a união havia sido adiada, sendo que apenas uma das etapas do processo havia sido postergada) e o depoimento de Lula a respeito de Hitler e Khomeini, retirado do contexto da entrevista integral, dando a impressão de que o então candidato à presidência do Brasil admirava 
homens conhecidos por tentarem se manter no poder mesmo à custa do assassinato de pessoas com opiniões opostas.

Ao considerar os resultados do exercício crítico durante esses 30 anos, é primordial situá-lo no contexto brasileiro, marcado pela reabertura democrática; Plano Real de 1994; pelo impedimento de dois presidentes da República e pela prisão de outros dois (sendo que um foi solto em seguida); denúncias de corrupção nos três Poderes (Legislativo, Executivo e Judiciário); conquista do governo, durante 14 anos, por políticos de tradição progressista; diminuição da miséria e posterior instabilidade econômica; recente emergência de forte movimento conservador e governo de extremadireita. A imprensa foi acusada ora de fazer publicações sensacionalistas sobre escândalos de corrupção, ora de subestimar os problemas, por vezes de manifestar apoio sutil a políticos conservadores, e em outros momentos de se prestar ao papel de militante das causas progressistas... Em suas colunas, os ombudsmans buscaram avaliar aspectos, expor nuances de cada situação, demonstrando, em alguns casos, numa mesma reportagem, erros e acertos, informações que poderiam ser interpretadas negativamente por leitores de diferentes posicionamentos políticos.

De forma geral, não é possível afirmar que a Folha aprenda com os próprios erros, mesmo quando eles são assumidos e criticados publicamente. Situações como a falta de didatismo e contextualização das informações ou a confiança em fontes não identificadas e destaque a denúncias não comprovadas repetem-se ao longo desses 30 anos. Entretanto, as reincidências não invalidam a crítica. Se os próprios jornalistas parecem não aprender com ela, pressupõe-se que os leitores possam aprender - ou mesmo os novos profissionais integrantes da equipe do jornal.

\section{Considerações finais}

Ao estudar as críticas da cobertura jornalística da Folha nessas três décadas, confirma-se, pelo tema do noticiário avaliado, que o Brasil é um país desafiador e esses desafios impactam na cobertura e na crítica que se faz a essa cobertura. Entende-se, todavia, que o desenvolvimento como sociedade democrática passa, inevitavelmente, pelo fortalecimento do jornalismo e este, pelo avanço da crítica de mídia nas diferentes modalidades. Conclui-se que a dimensão política e pedagógica desse exercício crítico, tornado público há 30 anos, seja suficiente para justificar sua relevância no contexto midiático brasileiro. 
Embora seja tentador, não interessa aqui fazer uma defesa obstinada da autocrítica jornalística. A proposta desta pesquisa foi ajudar a compreender de que modo a crítica de mídia, no formato da coluna de ombudsman, é realizada há 30 anos pelo jornal de maior circulação no país. As 71 colunas com críticas fortes, passíveis de serem lidas em profundidade, revelaram que o maior número de críticas ocorre na segunda década e que a maioria das coberturas criticadas trata de política.

Os seis principais problemas apontados podem ser identificados como falta de informações, destaque para informação de pouca relevância, informações distorcidas, informações erradas, falta de destaque para informação relevante e tratamento desigual para situações equivalentes. Assim como a quantidade de críticas, os temas das coberturas criticadas e os problemas apontados variam com o passar dos anos.

Analisando essas alterações, chega-se a muitas considerações, entre elas, a de que a ocorrência de mais críticas fortes a partir da segunda década indica uma mudança de comportamento dos ombudsmans, que passam a ter como foco a Folha (em vez de outros veículos). Três problemas (falta de informações, destaque para informação de pouca relevância e informações erradas) são mais criticados na segunda década e menos na terceira. Essa diminuição, entre abril de 2009 e abril de 2019, denota, possivelmente, aprendizado profissional nessa área e maior acesso à internet e a outras formas de melhorar a apuração e a checagem.

Vale lembrar, por outro lado, que a incidência de outros dois problemas (informações distorcidas e falta de destaque para informação relevante) aumenta da segunda para a terceira década, quando também passa a ser criticado um novo tipo de equívoco: tratamento desigual para situações equivalentes. Esse aparente retrocesso no desempenho jornalístico da Folha pode sinalizar um problema mais grave, influenciado por posicionamentos políticos e editoriais da empresa, já que o período coincide com a maior parte dos anos sob o governo do Partido dos Trabalhadores. Mas para apresentar uma conclusão nesse sentido, seriam necessários outros elementos de análise.

Por ora, a expectativa é ter cumprido o objetivo de apresentar os principais resultados da pesquisa acerca das colunas de ombudsman da Folha de S. Paulo entre 1989 e 2019. Houve um investimento para oferecer a síntese dos temas e problemas abordados nas críticas durante 30 anos. No entanto, como o material das colunas é vasto e rico em possibilidades de novas investigações, muito há para continuar observando. Com base no referencial teórico aqui utilizado e na magnitude empírica descoberta, 
reafirma-se a relevância social de pesquisas como essas na medida em que avançam no entendimento da crítica de mídia (nesse caso, a especializada, de ombudsman), fazendo, por sua vez, a crítica acadêmica.

\section{Referências}

AZEREDO, Diana. Alberto Dines e o papel da crítica jornalística na imprensa brasileira. In: HRENECHEN, Vanessa Cristina de Abreu Torres (org.). Ciências da Comunicação. Ponta Grossa (PR): Atena Editora, 2019a. p. 89-102. Disponível em: https://www.atenaeditora.com.br/wp-content/uploads/2019/03/e-book-

Ci\%C3\%AAncias-da-Comunica\%C3\%A7\%C3\%A3o.pdf. Acesso em: 14 jul. 2019.

AZEREDO, Diana. A crítica da cobertura jornalística nos 30 anos da coluna de ombudsman da Folha de S. Paulo. 2019. 263 f. Dissertação (Programa de PósGraduação em Jornalismo) - Universidade Federal de Santa Catarina, Florianópolis, 2019b. Disponível em: http://tede.ufsc.br/teses/PJOR0132-D.pdf. Acesso em: 05 jun. 2020 .

BARDIN, Laurence. Análise de conteúdo. Lisboa: Edições 70, 1977.

BERTRAND, Claude-Jean. O arsenal da democracia: sistemas de responsabilização da mídia. Bauru: Edusc, 2002.

BITTENCOURT, Wania Célia. Critérios de crítica de mídia noticiosa: uma investigação a partir da polêmica do livro didático. 2014. 162 f. Dissertação (Programa de Pós-Graduação em Jornalismo) - Universidade Federal de Santa Catarina, Santa Catarina, 2014. Disponível em: https://repositorio.ufsc.br/handle/123456789/128802. Acesso em: 05 jun. 2020.

BITTENCOURT, Wania Célia; SILVA, Gislene. Apontamentos históricos sobre crítica de mídia noticiosa. Novos Olhares, São Paulo, v. 4, n. 2, p. 6-18, 2015. Disponível em: http://www.revistas.usp.br/novosolhares/article/view/104107. Acesso em: 05 jun. 2020.

BRAGA, José Luiz. A sociedade enfrenta sua mídia: dispositivos sociais de crítica midiática. São Paulo: Paulus, 2006.

CARRATO, Ângela. Jornais, ombudsman e cidadania: um balanço (provisório) dos últimos 10 anos no Brasil. In: CONGRESSO BRASILEIRO DE CIÊNCIAS DA COMUNICAÇÃO, 25., 2002, Salvador. Anais [...] São Paulo: INTERCOM, 2002. Disponível em: http://www.portcom.intercom.org.br/pdfs/7692146403498281289200462954739180787 7.pdf. Acesso em: 05 jun. 2020.

COELHO, Jairo Faria Guedes. Ouvidoria na TV: A experiência dos canais privados colombianos. 2013. 193 f. Dissertação (Programa de Pós-Graduação em Ciências da Comunicação) - Faculdade de Comunicação da Universidade de Brasília, Brasília, 2013. Disponível em:

http://bdtd.ibict.br/vufind/Record/UNB_52d5ded78328c2f7268365c8806fce12. Acesso em: 05 jun. 2020. 
DINES, Alberto. Mediacriticism: Um espaço mal-dito. In: SILVA, Carlos Eduardo Lins da. Comunicação, hegemonia e contra-informação. São Paulo: Editora Cortez, 1982. p. $147-154$.

GENRO FILHO, Adelmo. O segredo da pirâmide: para uma teoria marxista do jornalismo. Florianópolis: Insular, 2012.

LAGE, Nilson. Ideologia e técnica da notícia. Petrópolis: Vozes, 1979.

LOURES, Ângela da Costa Cruz. Pequena história da crítica de mídia no Brasil. In: CHRISTOFOLETTI, Rogério; MOTTA, Luiz Gonzaga (org.). Observatórios de mídia: olhares da cidadania. São Paulo: Paulus, 2008.

MENDES, Jairo Faria. O ombudsman e o leitor. Belo Horizonte: Ed. O lutador, 2002.

MESQUITA, Mário. Um mediador português na imprensa diária. In: BERTRAND, Claude-Jean. O arsenal da democracia. Bauru: Edusc, 2002. p. 231-239.

OLIVEIRA, Maria Madalena da Costa. Metajornalismo... ou quando o jornalismo é sujeito do próprio discurso. 2007. 347 f. Tese (Doutorado) - Universidade do Minho, Braga, 2010. Disponível em: http://repositorium.sdum.uminho.pt/handle/1822/7035. Acesso em: 05 jun. 2020.

SILVA, Gislene; CALERO, María Luisa Sánchez. La crítica de la cobertura periodística en las revistas académicas españolas. Estudios sobre el Mensaje Periodístico, Madri, v. 24, n. 1, p. 887-903, 2018. Disponível em:

https://revistas.ucm.es/index.php/ESMP/article/view/59985. Acesso em: 05 jun. 2020.

TRAQUINA, Nelson. Teorias do Jornalismo: porque as notícias são como são. 3. ed. Florianópolis: Insular, 2012. v. 2.

Submetido em: 08.10.2019

Aprovado em: 26.01.2020 